\title{
GÊNERO E PRODUÇÃO DE PRESENÇA HOMOERÓTICA NA CONSTRUÇÃO DO MASCULINO EM MORTE EM VENEZA, DE THOMAS MANN
}

\author{
Greicy Pinto Bellin* \\ Jonhes Tadeu Gomes**
}

RESUMO: Este artigo pretende analisar as relações entre homoerotismo, ambiência e Stimmung na construção do masculino na novela Morte em Veneza, de Thomas Mann (1911). Pretende-se trabalhar com os conceitos de gênero e performance propostos por Joan Scott, Teresa de Lauretis e Judith Butler, respectivamente, relacionando-as aos conceitos desenvolvidos por Hans Ulrich Gumbrecht em Atmosfera, ambiência e Stimmung (2014). Nosso objetivo é compreender o papel desempenhado pelas construções de gênero na representação de um homoerotismo construído por meio de elementos materiais do texto relacionados à ambiência da narrativa, e por meio de elementos da mitologia grega, perceptíveis no texto de Thomas Mann.

PALAVRAS-CHAVE: Ambiência; Gênero; Homoerotismo; Performance; Stimmung.

\section{Introdução}

Na Antiguidade Clássica, a pederastia era uma prática em que ocorria a relação entre um jovem e um homem de meia idade com vistas a introduzir o jovem na dinâmica da masculinidade e da vida adulta. Nesse tempo, o envolvimento entre pessoas do mesmo sexo não era visto como doença e/ou como subversão, sendo uma prática arraigada nos costumes da sociedade. Na literatura, o homoerotismo encontrou representação consistente nos poemas de Safo, poeta de Lesbos que tematizou a paixão entre duas mulheres de forma intensa e arrebatadora, no Satyricon, de Petrônio e séculos mais tarde no Decameron, de Giovanni Bocaccio, em vários sonetos de William Shakespeare, e no romance O retrato de Dorian Gray, de Oscar Wilde. O homoerotismo também aparece em obras fundamentais da literatura brasileira, entre elas Dom Casmurro, de Machado de Assis, e Grande sertão: veredas,

\footnotetext{
* Professora titular do Programa de Pós-Graduação em Teoria Literária e do curso de graduação em Letras Português-Inglês da Uniandrade. Realizou estudos de pós-doutoramento em Estudos Literários na Universidade Federal do Paraná (UFPR) e naUniversidade Estadual de Campinas (Unicamp).

** Mestrando do Programa de Pós-Graduação em Teoria Literária da Uniandrade. Professor de língua portuguesa da Prefeitura Municipal de Piraquara, Paraná.
} 
de Guimarães Rosa, o que evidencia a importância do tema, bem como a relevância de uma análise que o perceba no interior de configurações de gênero que auxiliem a compreendêlo.

O objetivo deste artigo será analisar as relações homoeróticas em Morte em Veneza, dentro da perspectiva dos estudos de gênero em associação com os conceitos de ambiência e Stimmung expostos por Hans Ulrich Gumbrecht (2014). A hipótese central é a de que as construções do homoerotismo masculino na novela de Thomas Mann são permeadas por elementos materiais como atmosfera e ambiência, relacionados à cidade de Veneza, espaço no qual transcorre a narrativa, e que exerce papel preponderante no enredo. As reflexões de Gumbrecht, associadas às de Judith Butler em Problemas de gênero: feminismo e subversão da identidade, bem como a ideia de performance, analisada por Paul Zumthor em Performance, recepção e leitura, fornecerão as bases materiais para a análise do gênero enquanto construção social associado a um Stimmung de decadência, putrefação e morte.

\section{O gênero enquanto categoria de análise, performance e Stimmung: algumas consi-} derações teóricas

O conceito de gênero é de grande relevância na teoria literária contemporânea, sendo de fundamental importância para a compreensão da representação homoerótica em Morte em Veneza. Para Joan Scott, no famoso artigo: "Gênero: uma categoria útil de análise histórica" (1989), o conceito de gênero aparece primeiramente com as feministas americanas, conferindo um caráter fundamentalmente social às distinções outrora baseadas no sexo. Dessa maneira, o termo gênero introduz uma noção relacional no vocabulário do feminismo, permeado por uma série de debates que tendiam, no momento de sua configuração, a confinar as análises a oposições fixas entre masculino e feminino. O gênero surge como categoria de análise nos anos 1990 visando neutralizar estas relações dentro de uma doxa interpretativa que percebe como produto de construções sociais: "O gênero é um elemento constitutivo de relações sociais baseadas nas diferenças percebidas entre os dois sexos, e o gênero é uma forma primeira de significar as relações de poder” (SCOTT, 1989, p. 21). Na visão de Teresa de Lauretis, no artigo "A tecnologia do gênero", "as concepções 
culturais de masculino e feminino como duas categorias complementares formam, dentro de cada cultura, um sistema de gênero, um sistema simbólico ou um sistema de significações que relaciona o sexo a conteúdos culturais de acordo com valores e hierarquias sociais" (LAURETIS, 1994, p. 211). A literatura poderia ser considerada um dos sistemas de significação referenciados pela autora, na qual forma e conteúdo se associam para veicular as representações de gênero presentes na sociedade.

Ainda para Lauretis, o gênero seria uma representação, e tal representação seria tanto o produto quanto o processo de sua construção. A autora parte do conceito de tecnologia, tal como exposto por Michel Foucault, que a define como "um conjunto de técnicas para maximizar a vida", criada e desenvolvida "pela burguesia a partir do final do século XVIII para assegurar a sobrevivência da classe e a continuação da hegemonia" (LAURETIS, 1994, p. 220). Lauretis considera o cinema como tecnologia de construção de gênero na sociedade contemporânea, uma vez que lança mão de estratégias utilizadas pelos cineastas e diretores na representação da figura feminina. Para a autora, a construção do gênero pelas tecnologias é permeada por ideologia, a qual, na visão de Althusser, também citado pela autora em seu artigo, "representa não o sistema de relações reais que governam a existência de indivíduos, e sim a relação imaginária daqueles indivíduos com as relações reais em que vivem" (LAURETIS, 1994, p. 212).

O conceito de gênero será objeto de expressiva desconstrução por Judith Butler em Problemas de gênero: feminismo e subversão da identidade. Em sua reflexão, Butler afirma que há uma construção convencional de gênero caracterizada pela heterossexualidade compulsória, isto é, por uma obrigação, na maioria das vezes implícita, de se obedecer a padrões sociais e sexuais advindos desta mesma heterossexualidade. Este pensamento não apenas transformou Butler em precursora do que depois se tornaria conhecido como teoria queer, como também abriu as possibilidades para a análise das materialidades nas construções de gênero, considerando que a autora lança mão do conceito de performance para compreender como o gênero é construído, já analisado por Paul Zumthor em Performance, recepção e leitura (2007). Zumthor, citando Urbino, afirma que "performance [...] refere a realização 
de um material tradicional conhecido como tal. Eu traduzo: performance é reconhecimento. A performance realiza, concretiza, faz passar algo que eu reconheço, da virtualidade à atualidade" (ZUMTHOR, 2007, p. 31). Para Judith Butler, no artigo "Os atos performativos e a constituição do gênero":

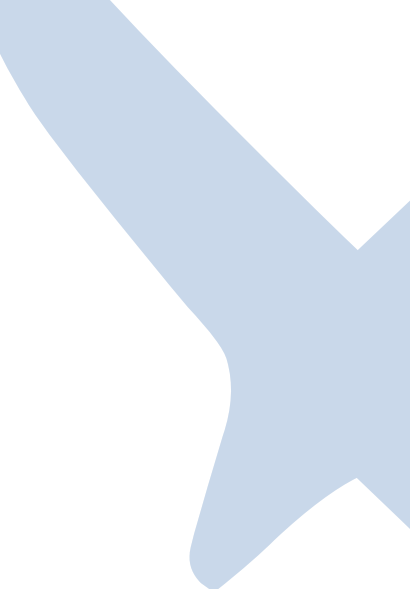

o gênero, ao ser instituído pela estilização do corpo, deve ser entendido como a maneira cotidiana por meio da qual gestos corporais, movimentos e encenações de todos os tipos constituem a ilusão de um "eu" generificado permanente. Essa formulação desloca o conceito de gênero para além do domínio de um modelo substancial de identidade para um modelo que exige uma concepção de temporalidade social constituída. Significativamente, se o gênero é instituído por atos internamente descontínuos, o aparecimento da substância é precisamente isso: uma identidade construída, uma realização performativa na qual a plateia social cotidiana, incluindo os próprios atores, vem a acreditar, além de performar como uma crença. Se o fundamento da identidade de gênero é a repetição estilizada de atos no tempo, e não uma identidade aparentemente homogênea, existem possibilidades de transformar o gênero na relação arbitrária entre esses atos, nas várias formas possíveis de repetição e na ruptura ou repetição subversiva desse estilo. (BUTLER, 2018, p. 3)

Desconstruindo a doxa social-construtivista que permeia o entendimento sobre o gênero, a reflexão de Butler aponta para a impossibilidade de um homem ou mulher acordar pela manhã e incorporar uma identidade previamente construída, como parecem sugerir os teóricos do gênero enquanto categoria de análise, entre eles a própria Joan Scott. $\mathrm{Na}$ visão de Hans Ulrich Gumbrecht, Butler é uma teórica construtivista que considera o corpo enquanto aparato semiótico, o que representa um passo importante no resgate da materialidade do texto:

Butler quer dizer que não basta uma simples decisão para alterar o gênero de uma pessoa, como o construtivismo parece sugerir; são necessárias formas de comportamento e de ação, mantidas ao longo do tempo (nesse contexto, Butler recorre ao conceito de "performance"), capazes de moldar e de produzir diferentes formas e identidades corporais. Mas, ao passo que Butler é bastante explícita na crítica ao construtivismo, também é claro que a autora está ciente do tabu discursivo que protege a posição construtivista. (GUMBRECHT, 2014, p. 86) 
A materialidade textual, um dos interesses de pesquisa de Gumbrecht deste o início de sua produção acadêmica, é de fundamental relevância para que possamos compreender a construção do homoerotismo em Morte em Veneza, especialmente considerando que a ambiência da cidade interfere nas disposições de ânimo de Gustav von Aschenbach, que involuntariamente escolhe o caminho da morte ao se apaixonar pelo jovem Tadzio e decidir segui-lo pelas ruas de Veneza, deambulação na qual come morangos estragados e propicia, com isso, sua contaminação com a cólera indiana que assolava a cidade. Para Gumbrecht:

O sentido da audição é uma complexa forma de comportamento que envolve todo o corpo. A pele, e assim como modalidades de percepção baseadas no tato, tem funções muito importantes. Cada tom percebido é claro, uma forma de realidade física (ainda que invisível) que "Acontece" aos nossos corpos e que, há mesmo tempo, os "envolve". Outra dimensão de realidade acontece aos nossos corpos de modo semelhante é o clima atmosférico. Precisamente por isso, muitas vezes as referências e ao tempo atmosférico aparecem na literatura quando os textos tornam presentes - ou começam a refletir sobre - os estados de espírito e as atmosferas. (GUMBRECHT 2014, pg. 12-13)

O Stimmung pode ser compreendido como um conjunto de fatores materiais, concretos ou não, que causam um efeito sobre o corpo, induzindo, com isso, determinadas sensações psíquicas que encontram respaldo em questões sociais. No caso de Morte em $V e$ neza, uma das sensações mais evidentes é a vergonha de Aschenbach em relação à sua paixão proibida por Tadzio, vergonha esta que pode ser correlacionada à realidade social da época, em que a homossexualidade era considerada um tabu. Na narrativa de Thomas Mann, o homoerotismo é respaldado pelas referências a Fédon, de Platão, a partir das quais assume dimensão simbólica ao remeter à busca incessante pelo ideal de arte, materializado, por sua vez, pela beleza inquestionável de Tadzio.

Outro aspecto da reflexão de Gumbrecht que deve ser levado em consideração neste artigo é a análise de Morte em Veneza em Atmosfera, ambiência e Stimmung: por um potencial oculto na literatura (2014). Para o autor:

O herói da obra, Gustav von Aschenbach, percebe a beleza de Tadzio, o efebo polonês, como evento de boa sorte e de inspiração. 
Isso pode ser entendido como a abertura inaugural de uma atmosfera de idealismo - uma resposta inicial positiva à questão de saber o que poderia seguir-se à mestria, depois de esta ter sido demonstrada. Essa seria - acreditava Mann - a abertura do protagonista ao poder da pura beleza. Porém, a queda de Aschenbach para um estado de pecado - o seu lapso em relação à ideia normativa - dá-se na medida em que Tadzio, o seu "deus delicado", se transforma num ídolo que, em última análise, vai rebaixando o seu admirador até que este não passe de um "suado e cosmeticamente rejuvenescido perseguidor de rapazes”. (GUMBRECHT, 2014, p. 96)

A “atmosfera de idealismo" à qual se refere o autor é substituída, do meio para o fim da novela, pela atmosfera de decadência associada à homossexualidade, reforçadas pela descrição da fétida e contaminada Veneza, a qual acaba por contribuir decisivamente para a morte fulminante de Aschenbach:

Atmosferas e ambientes, como vimos, são disposições e estados de espírito que não estão sujeitos ao controle por parte do indivíduo que afetam. A linguagem do dia a dia, assim como a linguagem literária, associam-nos - de modo quase obsessivo - com as mudanças no clima meteorológico ou com a variação dos sons da música. Stimmung é a dimensão mais concreta - e, por isso mesmo, talvez a mais "literária" - em que decorre a paixão de Aschenbach. A concordância complementar das descrições meteorológicas e das fases de amor pelas quais ele vai passando - que vão da admiração platônica à submissão absoluta (à distância, claro) - é tão habilmente engendrada - com tal mestria autoral - que o leitor quase não repara no improvável que essa convergência, de fato, é. (GUMBRECHT, 2014, p. 98)

Há, de fato, estreita correlação entre os estágios da paixão de Aschenbach por Tadzio e a condição atmosférica de Veneza, correlação esta que, conforme demonstraremos, também se observa em relação às configurações de gênero observadas ao longo da novela, as quais oscilam entre um modelo de masculinidade hegemônica e uma subalternização do escritor em relação a seu objeto de desejo, materializada, por exemplo, na ida ao barbeiro quase ao término da novela. Estas configurações encontram na performance seu principal veículo de materialização, o que corrobora a importância dos elementos materiais na análise do homoerotismo em Morte em Veneza. 


\section{Homoerotismo, gênero e Stimmung na construção do masculino em Morte em Ve-} neza

Paul Thomas Mann nasceu em 06 de junho de 1875 em Zübeck, Alemanha, e morreu em 12 de agosto de 1955 em Zurique, na Suíça. Filho de Thomas Johann Henrich Mann, que foi senador e comerciante de cereais, Júlia da Silva Bruhns Mann, de nacionalidade brasileira, descendente de alemães e negros. No ano de 1891, Mann perde seu pai e sua família muda para Munique. Ele permanece em sua cidade natal e tenta se engajar nos estudos. No Liceu Katharineum, funda a revista Tempestade de Primavera, ao lado de seu colega Otto Grantoff. Mais tarde, se reuniu novamente com sua família e trabalhou em um escritório de seguros. Nesse período o autor iniciou seus estudos de arte e literatura na Universidade de Munique.

A primeira obra escrita por Mann foi Queda, publicado em 1894 na revista A Sociedade, de Munique. Após dois anos, na Itália, Mann escreve Os Buddenbrooks: Decadência de uma familia (1901), romance que lhe rendeu um Prêmio Nobel de Literatura no ano de 1929. Em seu retorno para a Alemanha, escreveu Tristão (1902), Tônio Kroeger (1903), Florença (1903), e O Sangue dos Walsungs (1905). No ano de 1905, Mann se casou com Katia Pringsheim e, após o seu casamento, publicou as obras Sua Alteza Real (1909), e Morte em Veneza, considerada uma das melhores composições da literatura alemã, no ano de 1912. Entre suas composições publicou, também, o conto "Um homem e seu cachorro" (1918).

No ano de 1924, Mann compõe uma de suas maiores obras: $A$ montanha mágica, a qual foi amplamente reconhecida por público e crítica. Exilado na França, Mann escreveu, ainda, o romance José e seus irmãos, inspirado no pensamento bíblico e na reelaboração das histórias do Gênesis. No ano de 1938 viajou para os Estados Unidos, e só veio a retornar para a Europa no ano de 1947, onde morou na Inglaterra. Em 1952, mudou-se para Zurique e publicou $O$ eleito. Em 1954, terminou seu último livro, As confissões de Félix Krull. Mann faleceu em Zurique, em 1955, sendo até hoje considerado um dos maiores romancistas em língua alemã.

Morte em Veneza pode ser interpretado como um romance autobiográfico, tendo em vista o suposto envolvimento de Thomas Mann com rapazes durante férias passadas 
na Itália, mais especificamente no hotel Lido, em Veneza, onde transcorre a ação da novela que será analisada neste artigo. O envolvimento homossexual também se observa em $A$ montanha mágica, na suposição de que o romance seria o retrato da primeira paixão de Mann por Wilri Timppe. Em Morte em Veneza a paixão de Aschenbach por Tadzio se reveste de componentes platônicos e extremamente idealizados dada não apenas a vergonha sentida por um senhor de cinquenta anos no auge de seu sucesso como escritor, mas a busca frenética deste mesmo escritor por um ideal artístico de beleza, busca esta que acaba por leválo à morte ao final da narrativa.

Morte em Veneza retrata um episódio na vida do protagonista Gustav Aschenbach, ou von Aschenbach, que, após comemorar seu quinquagésimo aniversário, decide sair em viagem pela Europa. Observa-se, ao longo da narrativa, o estabelecimento de uma significativa ligação com o mundo filosófico grego por meio das referências a $O$ Fédon, e das constantes remissões à mitologia grega e romana, materializadas, por exemplo, nas representações dos barqueiros do canal de Veneza. Von Aschenbach, ao decidir permanecer em Veneza, se apaixona por Tadzio, um jovem polonês de quatorze anos que se hospeda no luxuoso hotel Lido com sua mãe e suas irmãs, e cuja presença se revela altamente arrebatadora e obsedante para o escritor.

Aschenbach é descrito como um literato cuja vida foi intensamente voltada às artes, sendo também descrito como uma pessoa bastante doente e com necessidade de cuidados médicos desde a sua juventude. Esta condição se reflete em sua aparência franzina, o que aponta para uma configuração de gênero que desestabiliza a masculinidade hegemônica por remeter à fragilidade física e psíquica do demiurgo que se entrega ao labor artístico de forma plena e intensa:

Gustav Aschenbach era o poeta de todos aqueles que trabalhavam à margem do esgotamento, dos oprimidos, já aniquilados, ainda se mantendo de pé, de todos estes moralistas de produção que, ao menos durante algum tempo, ganham os efeitos de grandeza pelo arrebatamento da vontade e da inteligente administração, apesar de físico meio franzino e precário. (MANN, 1979, p. 97)

Aschenbach vive em busca de algo que o faça ascender enquanto artista, e de uma dor que o permita viver com maior intensidade, o que remete a um ambiente de espera e 
suspense na narrativa: "sobre o novo tipo de herói que este autor preferia, em diversas e repetidas aparições individuais, um analista inteligente escrevera: que era a concepção de uma juvenil masculinidade intelectual” (MANN, 1979, p. 96). Percebe-se, neste sentido, uma configuração de gênero que associa masculinidade e intelecto, e que percebe o feminino enquanto objeto de inspiração artística, o que irá se materializar na representação da paixão arrebatadora de Aschenbach por Tadzio durante o seu idílio pela Itália.

O trecho citado acima deixa claro que o protagonista possui um padrão rígido de comportamento, o qual se afrouxa quando decide tirar férias: "Logo em seguida foi refreado e posto em ordem o que o acometera tão tarde e repentinamente, pela razão e disciplina exercida desde moço" (MANN, 1979, p. 91). O trecho a seguir revela possíveis manchas no passado do escritor, deixando subentendido que cometera erros em sua juventude, e que havia alcançado a dignidade com o passar do tempo:

Quando jovem ele fora rude com o tempo, e, mal aconselhado por este, tropeçara publicamente, fizera erros, expusera-se, infringira contra o tato e a prudência, em palavras e obras. Mas alcançara a dignidade pela qual, como afirmava, todo grande talento tem inato um impulso e um espinho natural. (MANN, 1979, p. 97)

Apesar de a passagem não deixar claro, é possível que os erros e a falta de tato e prudência do jovem Aschenbach se refiram a relacionamentos com pessoas do mesmo sexo. Estabelece-se, em suma, uma atmosfera associada à ideia de homossexualidade como doença e decadência, reforçada, conforme já explicitado, pela descrição de uma Veneza infestada pela cólera e pelos odores putrefatos que multiplicam a contaminação da moléstia.

O início da novela traz, ainda, indícios de uma ambiência bélica que pairava sobre a Europa, o que faz sentido se considerarmos que a narrativa foi escrita em 1911, três anos antes da eclosão da Primeira Guerra Mundial, ainda que o trecho a seguir não explicite o ano em que a história se passa:

Gustav Aschenbach, ou Von Aschenbach, como era oficialmente seu nome desde seu quinquagésimo aniversário, fizera um longo passeio sozinho, de sua residência na Prinzregententrasse, em Munique, numa tarde primaveril do ano de $19 . .$. , que, durante meses, 
mostrara ao nosso continente uma fisionomia anunciadora de conflitos. (MANN, 1979, p. 87)

A atmosfera climática, materializada na descrição do que Gumbrecht chama de "Föhn" ou "vento seco", condição típica da cidade de Munique que simula um auge do verão em pleno mês de maio, exerce poderosa influência sobre o espírito do escritor, afrouxando a rigidez característica da masculinidade hegemônica e dando ensejo à ideia de tirar férias:

Era o princípio de maio e, depois de semanas úmidas e frias, aparecera um falso verão. O Englischer Garden, apesar de ainda fracamente frondoso, estivera mofento como em agosto e, nas proximidades do centro, cheio de carros passeantes. No Aumeister, para onde caminhos mais e mais abonados o levaram, Aschenbach ficou durante algum tempo olhando o restaurante animado pelo povo, ao lado do qual paravam alguns coches e carruagens; de lá, com o sol poente, tomara o caminho de volta pelo lado de fora do parque, sobre o prado aberto, e, em frente ao cemitério do norte, esperou, porque se sentia cansado e de Foehring ameaçava um temporal, o bonde que devia leva-lo, em linha reta, de volta à cidade. (MANN, 1979, p. 87-88)

Além da condição climática, observa-se uma arquitetura fúnebre na descrição do cemitério, o que confirma a presença de elementos ligados à morte e de todos os elementos relacionados a ela, prenunciando o desfecho trágico da narrativa. É neste momento que Aschenbach identifica o homem ruivo que o leva a tomar a decisão definitiva de viajar para sair de sua monótona rotina:

[...] De estatura mediana, magro, imberbe e de nariz extraordinariamente arrebitado, o homem pertencia ao tipo ruivo e possuía pele leitosa e sardenta peculiar a este. Evidentemente, não era bávaro como indicava, no mínimo, o chapéu de palha com aba larga e reta, que cobria sua cabeça, dando-lhe um aspecto de estrangeiro vindo de longe. (MANN, 1979, p. 89)

A aparência do ruivo causa estranhamento no protagonista, provocando uma sensação permeada por elementos relacionados à atmosfera e ambiência: "[...] que de repente esforçou-se em idealizar: ele via, via uma paisagem, uma região tropical pantanosa sob o céu pesado, úmido, exuberante e descomunal, uma espécie de selva antediluviana, composta de ilhas, pântanos e braços fluviais lamacentos” (MANN, 1979, p. 90). A descrição 
da indumentária do homem ruivo é também relevante no que diz respeito à criação de uma performance e de uma construção de gênero que reforça a imagem do macho viril, expressa pela ênfase dada ao pomo-de-adão:

\begin{abstract}
Porém, trazia a mochila, tão em uso no país, afivelada aos ombros, um terno cintado de pano não pisoado, de cor amarelada, parecendo trazer uma capa de chuva sobre o antebraço esquerdo, que encostava na cintura; de pés cruzados, firmava à direita e obliquamente contra o chão uma bengala com ponta de ferro, cujo castão apoiava na cintura. Com a cabeça erguida, de modo que, crescendo a camisa esporte solta, aparecia seu pescoço magro, sobressaindo, forte e nu, o pomo-de-adão. (MANN, 1979, p. 89)
\end{abstract}

Trata-se de parte do corpo mais visível em homens por terem ossos maiores e proeminentes, vozes mais fortes e ossos anatomicamente maiores do que os das mulheres. Aschenbach experimenta uma forte sensação de adrenalina ao olhar para o estranho, construída pelos elementos materiais ligados ao corpo e à presença do deste: "Fosse que o aspecto de viajante do estranho tivera efeito sobre sua imaginação ou outra qualquer influência física ou moral, surpreendido, ficou cônscio de uma estranha expansão de seu íntimo” (MANN, 1979, p. 90).

O corpo, desta maneira, se transforma em aparato semiótico, sendo que o pomode-adão pode ser interpretado como a representação das leis vigentes em sociedade, remetendo à masculinidade hegemônica. Neste sentido, destaca-se, também, a descrição dos dentes do homem ruivo: "[...] ou porque se tratasse de uma deformidade física constante, seus lábios pareciam curtos demais, eram completamente recuados dos dentes, de modo que estes ficavam expostos, brancos e compridos, até a gengiva” (MANN, 1979, p. 89). Os dentes simbolizam força e saúde; porém, em uma boca com lábios curtos, denuncia uma deformidade que causa um estranhamento relacionado ao corpo, e que também exerce influência sobre o estado de espírito de Aschenbach.

A partir deste momento da narrativa, o ambiente que se observa é o de preparação para a ida a Veneza. A descrição dos barqueiros e dos demais tripulantes do barco é aspecto que chama a atenção no que concerne aos objetivos deste artigo, pois remete à ideia de performance associada ao Stimmung e à construção do gênero masculino: 
Numa cabina cavernosa da parte interna, artificialmente iluminada, para onde Aschenbach foi levado por um marinheiro corcunda, sujo e de sorridente solicitude, sentado atrás de uma mesa, o chapéu de lado na testa e um toco de cigarro no canto da boca, um homem de pera, fisionomia de um velho diretor de circo que, com pantomimas de leves atitudes comerciais, tomava nota dos documentos de identidades dos viajantes e tirava as passagens. (MANN, 1979, p. 102)

A performance torna-se clara por meio dos gestos, palavras, comportamento e vestuário do marinheiro corcunda e sujo, o qual, ao tomar nota da identidade dos viajantes, produz, ainda que simbolicamente, uma mudança no sentido e sentimento de cada tripulante, o que se confirma pelo estranhamento sentido por Aschenbach, bem como pelas significativas alterações em sua personalidade ao longo da viagem. O tripulante que mais chama a atenção do escritor é um senhor idoso que se faz passar por jovem em meio a um grupo de rapazes, e que remete ao que o protagonista irá se tornar em Veneza após se apaixonar por Tadzio: "Mal, porém, Aschenbach o observara melhor, notou, com uma espécie de horror, que o jovem era falso. Era velho, não havia dúvida. Rugas rodeavam os seus olhos e sua boca" (MANN, 1979, p. 103). Observa-se que, por não se permitir viver a sua homossexualidade devido à prevalência de configurações patriarcais hegemônicas, o escritor viverá uma experiência de mudança em seu corpo, a partir da qual tentará refrear o efeito do tempo em sua masculinidade. Os gondoleiros, por sua vez, remetem a um ambiente de repressão e tristeza e estão sempre cercados por uma energia negativa, representando também o interior de Aschenbach, frágil e debilitado por uma vida sempre cercada com muitas doenças e problemas.

A gôndola na qual o protagonista embarca se parece muito com um caixão, representando a passagem e a travessia para a morte. Veneza remete ao túmulo, pois é o lugar de destino do barco baladesco. O ambiente úmido e aquoso, o tempo nublado e caracterizado por descrições escuras, sombrias e úmidas produzem no personagem sensações de suspense e aventura. Cria-se uma atmosfera mórbida da qual o gondoleiro faz parte, o que permite a remissão à Caronte, barqueiro da mitologia grega que conduzia as almas ao mundo dos mortos: 
A estranha embarcação de tempos baladescos, tradicionalmente inalterada e tão singularmente preta como entre todas as coisas só o são os ataúdes - lembra caladas e criminosas aventuras sem noites murmurantes, lembra mais ainda a própria morte, macas e execuções sombrias e a última e silenciosa viagem. (MANN, 1979, p. 108)

Para Bachelard, "morrer é verdadeiramente partir, e parte bem, corajosamente, nitidamente, quando se segue o fluir da água, a corrente do largo rio. Todos os rios desembocam no Rio dos mortos" (BACHELARD, 1997, p. 77). Aschenbach segue esse fluxo das águas e deixa-se levar de encontro ao seu trágico fim, em águas que, assim como no mito de Caronte, dividem o mundo dos mortos e dos vivos. O trecho acima deixa claro que será a última viagem do personagem, auxiliando a construir a atmosfera de morte, doença e decadência que será validado pelo clima pestilento e putrefato da cidade de Veneza, cidade que produzia verdadeiro fascínio nos alemães à época de Thomas Mann. Goethe, Ibsen e Nietzsche são autores que também sentiram atração por Veneza, pois a Itália remetia a dias de sol, lugares quentes, povo acolhedor, isto é, um espaço propício para o desenvolvimento de grandes e arrebatadoras paixões.

A descrição do gondoleiro reforça o estereótipo de força e brutalidade associado a uma masculinidade hegemônica, estereótipo este construído a partir da performance do barqueiro, validada a partir da descrição do corpo enquanto aparato semiótico:

Vamos para a estação das barcas! - repetiu, virando-se por completo e erguendo os olhos para o rosto do gondoleiro, que, atrás dele, numa armação mais elevada se erguia contra o céu pálido. Era um homem com fisionomia descortês, brutal mesmo, vestido de azul à marinheira, com uma faixa amarela na cintura e um disforme chapéu de palha ousado e torto na cabeça, cujo trançado começava a abrirse. Sua formação de rosto, seu bigode louro, e crespo embaixo do nariz curto e arrebitado não lhe davam a aparência do tipo italiano. (MANN, 1979, p. 109)

O céu pálido, somado à descrição do gondoleiro que remete a Caronte, funciona como prenúncio da tragédia que se aproxima, considerando o pensamento do próprio Aschenbach em relação à performance brutal do barqueiro:: "“...] Isto é verdade, você navega bem. Mesmo se você só está de olho no meu dinheiro e, com uma pancada do remo pelas 
costas, mandar-me à casa dos Aides, você me levará bem” (MANN, 1979, p. 110). A passagem para a morte é construída a partir do desejo de Aschenbach da procura pela perfeição literária, ligada, por sua vez, à sabedoria e ao conhecimento. Tadzio é o personagem que personifica todo esse conhecimento e torna-se, por isso, a paixão idealizada que o protagonista projetou desde o início da novela:

Com surpresa, Aschenbach notou que o menino era perfeitamente belo. Seu rosto pálido e graciosamente fechado, circundando por cabelos cacheados, louros cor de mel, com o nariz reto, a boca suave, a expressão de seriedade divina, lembrava esculturas gregas dos, mais nobres tempos e da mais pura perfeição de forma; era de tão rara atração pessoal que o observador julgou nunca ter encontrado na natureza ou no mundo artístico uma obra tão bem sucedida. (MANN, 1979, p. 113)

As descrições do vestuário de Tadzio e suas irmãs apontam para as configurações de gênero que permeiam a construção dos personagens. Constrói-se uma identidade andrógina, manifesta em uma feminização materializada nos detalhes do rosto, sendo que o cabelo, a boca angelical, a superproteção de sua mãe e a falta de uma presença masculina corroboram para a construção desta identidade. A indumentária das irmãs, por outro lado, remete à repressão sexual da figura feminina em tempos de controle da sexualidade visando a procriação dentro do casamento:

O preparo das três moças, das quais a mais velha poderia ser considerada adulta, era acerbo e casto até a desconfiguração. Um traje simétrico de convento, cor de ardósia, meio comprido, sóbrio e propositalmente corte de mau gosto, com colarinhos brancos como único vivo, oprimia e impedia qualquer graciosidade do porte. Cabelo liso e fortemente colado à cabeça deixava os rostos, como os de freiras, vazios e sem expressão. Sim, havia uma mãe que aqui reinava, e ela nem pensava em usar a mesma severidade com o rapaz que lhe parecia necessária com as meninas. (MANN, 1979, p. 115)

As personagens femininas são, assim, subalternizadas pelo patriarcado, o qual se materializa na inserção em um contexto cristão, o que se observa por conta da menção a uma indumentária que lembra a de freira. A lei bíblica parece ser mais rigorosa para as moças, por isso elas são representadas muito próximas às carolas, ao passo que o jovem 
Tadzio usufrui de uma liberdade que, pelo menos em tese, o predisporia a ir ao encontro de outros relacionamentos, entre eles o relacionamento com outros homens, tendo em vista o alvorecer de sua sexualidade na idade de quatorze anos. A liberalidade (ou indiferença) de sua mãe se manifesta em relação ao cabelo que não é cortado e no fato de acordar tarde, ao contrário das irmãs, que acordam cedo: "Sim, havia uma mãe que aqui reinava, e ela nem pensava em usar a mesma severidade pedagógica sobre o rapaz que lhe parecia necessária com as meninas" (MANN, 1979, p. 114). A ausência de uma figura paterna na vida de Tadzio, a suposta ausência de uma iniciação sexual com meninas de sua idade, e também a relação que o rapaz mantinha com o amigo Jaschu consistem possíveis indícios de homossexualidade, percebida, na narrativa, como algo doentio e que remete à doença $\mathrm{e}$ ao crime, daí a já mencionada vergonha sentida por Aschenbach em relação aos seus sentimentos pelo jovem rapaz.

No primeiro contato visual entre Tadzio e o protagonista, o olhar cinza do menino polaco prevê a tragédia que se aproxima. A cor cinza aqui se aproxima do mar, elemento que, ao final da novela, representa o encontro entre Aschenbach e a morte:

Por um motivo qualquer, este se virou antes de passar pelo limiar, e, como ninguém mais permanecera na sala, seus estranhos olhos cinza-alvorada encontraram os de Aschenbach, que, de jornal sobre os joelhos, ensimesmado em contemplação, seguiu o grupo com seus olhos. (MANN, 1979, p. 115)

No sentido literal da tradução do nome Aschenbach, traduz-se o radical Aschen que significa cinza, e bach, praia. Percebe-se que o próprio nome do personagem carrega a imagem da morte associada à praia, o que vai, de fato, se concretizar ao final da narrativa. $\mathrm{O}$ efeito de morte associado à cor cinza é somado ao elemento água, que, por sua vez, remete ao inconsciente, sendo que a cor cinza seria, além disso, a intermediária entre a luz e a sombra (FREITAS, 2007)

O olhar e o contato com o garoto acendem dentro de Aschenbach um pensamento sobre a beleza e suas características, o que melhora o seu humor, o que é reforçado pelo ambiente em que se encontra: "Depois do jantar permaneceu no parque com seu perfume noturno, fumando, sentado, passeando; deitou-se cedo e passou a noite num sono contínuo 
e profundo, porém animado por vários sonhos" (MANN, 1979, p. 116). Ainda que à distância, Aschenbach passa a usufruir da companhia dos jovens, entre eles Jaschu, introduzido na narrativa no trecho a seguir:

Em sua companhia estavam mais ou menos dez amigos, meninos e meninas de sua idade e alguns mais jovens, tagarelando em polonês francês e também idioma dos Bálcãs. Mas era o seu nome que soava mais vezes. Evidentemente era querido, cortejado e admirado. Principalmente um deles, um polonês como ele, um rapaz forte, que era chamado por "Jaschu" ou coisa parecida, com cabelos pretos e cheios de brilhantina, parecia ser o mais próximo vassalo e amigo. (MANN, 1979, p. 121)

A descrição de Jaschu remete a uma configuração de masculinidade hegemônica e associada à força, configuração esta tensionada pela representação do rapaz como um vassalo aos pés de Tadzio, sendo que as meninas aparecem, mais uma vez, como personagens secundárias. A proximidade entre Jaschu e Tadzio se dá através do corpo e da presença: "Estando terminando, por esta vez, o trabalho de construção arenosa, saíram andando pela praia, estreitamente enlaçados e aquele que era chamado por "Jaschu" beijou o belo" (MANN, 1979, p. 121). Percebe-se que Tadzio é referido como o "belo", remetendo a uma construção homoerótica idealizada por Aschenbach, e que funciona como metáfora da busca pelo ideal artístico nunca dantes alcançado.

É importante salientar que o corpo e a anatomia de Tadzio, apesar de parecerem perfeitas aos olhos de Aschenbach, continham detalhes que remetiam a problemas de saúde. O rapaz é descrito como pálido e com dentes estragados, os quais apontam para uma juventude efêmera: "um tanto pontudos e pálidos, sem aquele esmalte da saúde e de singular transparência quebradiça que tem, às vezes, os dois anêmicos” (MANN, 1979, p. 123). O corpo pálido, por sua vez, aponta para o final de vida em plena juventude, o que pode ser interpretado como uma projeção da experiência de vida do próprio Aschenbach, que sofrera de problemas nervosos em sua juventude.

Observa-se, conforme já explicitado, a descrição de estados atmosféricos que não apenas influenciam o humor e a disposição física de Aschenbach, obrigando-o a deixar a 
cidade para depois retornar ao perceber que sua bagagem fora enviada de volta, como também reforçam a atmosfera de morte, doença e decadência associada ao homoerotismo como tabu: "O empurrar das pessoas no aperto incomodava o passante em vez distraí-lo. Quanto mais tempo andava mais se apoderava dele o detestável estado que o ar marinho com siroco pode produzir e que podem produzir que é ao mesmo tempo excitação e abatimento" (MANN, 1979, p. 124).

O "bafo morno do siroco", de acordo com Gumbrecht (2014), permeia vários momentos da narrativa, desde a travessia no barco rumo a Veneza até a estadia na cidade, corroborando a ideia de que há, na narrativa, a criação de uma Stimmung específica que acompanha o protagonista rumo à sua dissolução. A decisão de deixar Veneza é antecedida da seguinte descrição da condição climática:

O tempo não estava propício no dia seguinte. Havia vento terrestre. Sob um céu coberto, o mar estava numa calma embotada, como que enrugado, com o horizonte próximo e prosaico e tão recuado da praia que deixava exposta várias carreiras de extensos bancos de areia. Quando Aschenbach abriu sua janela, acreditou sentir o cheiro de podre da laguna. (MANN, 1979, p. 116)

Cabe salientar, com base na citação acima, que Aschenbach já havia estado em Veneza quando mais jovem e havia sido obrigado a partir devido ao mau tempo, o qual the havia deixado doente. O fato de retornar e permanecer em Veneza aponta, portanto, para um arrefecimento do padrão hegemônico de masculinidade que o havia motivado a deixar a cidade da outra vez, arrefecimento este que se reveste de um componente doentio materializado na morte por cólera no desfecho da narrativa. Em seu regresso ao hotel, Aschenbach acaba percebendo que o mar "adquirira uma coloração verde pálida, o ar parecia mais leve e limpo, a praia, com suas cabinas e barcos, mais coloridas, apesar de o céu continuar cinza” (MANN, 1979, p. 130). Tal descrição pode ser correlacionada com a alegria sentida pelo protagonista em seu retorno, a qual aumenta quando avista Tadzio pela janela "de terno de linho listrado com laço vermelho, vindo do mar pela divisão da praia e o caminho de madeira voltava ao hotel" (MANN, 1979, p. 130). 
Ainda assim, a cidade de Veneza continua a ser descrita como possuidora de um cheiro muito ruim: "Passou duas horas no seu quarto e viajou à tarde, para Veneza, com o vaporeto sobre a laguna, que cheirava podre" (MANN, 1979, p. 124). Apesar de sentir a atmosfera pestilenta da cidade e de estar prestes a adoecer, Aschenbach acaba permanecendo, pois, de certa forma, o perigo e a morte o mantinham presos a Veneza: “A atmosfera da cidade, este leve cheiro de pútrido de mar e lama, do qual se sentira tão impelido a fugir, respiro-o agora em fôlegos profundos, dolorosamente afetuosos” (MANN, 1979, p. 127). Para Gumbrecht, o próprio desenvolvimento da obsessão de Aschenbach por Tadzio, aliado à consciência do escritor que envelhece em seu fascínio pela juventude, "é comunicada ao leitor pelas mudanças meteorológicas de Veneza, amplificadas pelas diferentes formas de percepção", o que garante a grandeza da narrativa de Mann (GUMBRECHT, 2014, p. 97).

Percebe-se que, de fato, o ambiente doentio da cidade, caracterizado pela umidade, pelo sol, pelo mar cinza e pelo ar salino, produzia em Aschenbach um sentimento de êxtase e, ao mesmo tempo, de temor pela doença que se aproxima, e que o conduzirá ao mundo dos mortos ao final da narrativa. No auge de sua paixão pelo jovem polaco, a descrição do ambiente produzia um efeito de apego e paixão ainda mais intensa:

O sol queimava-lhe o rosto e as mãos, o ar salino fortalecia-lhe o sentimento; e, assim como antes aplicava de imediato numa obra todo o descanso que lhe proporcionava o sono, a alimentação ou a natureza, assim deixou agora tudo o que o sol, a ociosidade e o ar marinho lhe davam em cotidiano fortalecimento consumir-se, magnânimo e desgovernado, em êxtase e sentimento. (MANN, 1979, p. 139)

O próprio Aschenbach, na condição de escritor, cria uma atmosfera e uma ambiência em torno da presença de Tadzio, cuja remanescente infantilidade é representada pelas rosas, sendo que as cores vibrantes remetem à juventude do rapaz refletida sobre o mar:

Um espalhar de rosas começou à beira do mundo, um indizivelmente belo brilhar e florir, nuvens infantis, transfiguradas, translúcidas, oscilavam como servis gênios sobre o mar, que parecia flutuála em ondas para frente; lanças douradas apontavam de baixo para 
as alturas do céu; o brilho tornou-se brasa; silenciosamente, com supremo poder divino, brasa, ardor e labaredas chamejantes rolavam para cima e com cascos arrebatadores os cavalos sacros do irmão subiam pelo universo. (MANN, 1979, p. 140)

Estabelece-se, a partir da idealização característica da paixão platônica, e a despeito da distância existente entre os dois personagens, uma relação de poder na qual o mais jovem exerce total domínio sobre o mais experiente, especialmente considerando que Tadzio parece estar consciente do assédio silencioso de Aschenbach e não foge em nenhum momento de seu observador:

Às vezes também - e o idoso descobria-o com triunfo, com uma vertigem de sua razão e também espanto -, hesitante e cautelosamente ou rápido e repentino, como se quisesse tomá-lo de surpresa, virava a cabeça sobre o ombro esquerdo para o lado do admirador. Não encontrava seus olhos, pois uma preocupação vergonhosa forçava o desnorteado a controlar o seu olhar. (MANN, 1979, P. 151)

Apesar de receoso conforme demonstra o trecho acima, devido, em grande parte, ao tabu da homossexualidade, e temeroso acerca do declínio da masculinidade hegemônica, Aschenbach persegue seu ideal artístico com tanta determinação que já não se importa se isso pode causar sua morte: “[...] Pois ao apaixonado só preocupava que Tadzio talvez pudesse partir, e reconheceu assustado, que não saberia mais viver, se tal acontecesse” (MANN, 1979, p. 145). A determinação na projeção de seu ideal artístico é reforçada pela construção do masculino hegemônico patriarcal que torna ilícita a relação com uma pessoa do mesmo sexo. Aschenbach é plenamente consciente disso, percebendo com melancolia o que seria, em tese, o arrefecer da masculinidade hegemônica: “[...] Também agora e aqui, pensou neles; envolvido numa experiência tão ilícita, contido em tão cheia de garbo da decente masculinidade de seus caracteres, e sorriu melancólico" (MANN, 1979, p. 148).

A paixão do senhor experiente por um rapaz mais jovem se materializa em modificações significativas no vestuário e nos hábitos de higiene de Aschenbach, que assume uma nova performance social baseado no asco que sente em relação a seu corpo envelhecido, na esperança quase consciente de integrar-se a um universo muito distante do seu, e do qual se aproxima devido ao efeito exercido pela paixão: 
Adicionou ao terno alegres pormenores juvenis, usou pedras preciosas e perfume, gastava várias vezes por dia, muito tempo com sua toalete e descia para o jantar enfeitado, emocionado e curioso. À vista da doce juventude que o enfeitiçaria, sentia nojo se seu corpo envelhecido; o aspecto de seus cabelos grisalhos e seus traços marcados faziam-no sentir vergonha e desespero, impediam-no de refrescar-se e restabelecer-se fisicamente; visitava amiúde o barbeiro do hotel. (MANN, 1979, p. 163)

É importante observar, para a análise que estamos desenvolvendo, que o embelezamento da figura de Aschenbach é paralelo ao crescimento do rumor da cólera em Veneza, o que faz com que a cidade comece a esvaziar em plena temporada de verão:

A praça estava sob uma atmosfera sufocante, sem sol. Estrangeiros, na ignorância dos fatos, sentavam-se nos cafés ou estavam de pé cobertos de pombos em frente à igreja, e observavam como as aves, batendo com as asas, enxotando umas às outras, bicava os grãos de milho oferecidos no côncavo das mãos. Numa excitação febril, triunfante na posse da verdade, sentindo um gosto de nojo na boca e um vapor fantástico no coração, o solitário andava sobre os ladrilhos do esplêndido pátio, de um lado para o outro. (MANN, 1979, p. 159-160)

A partir deste momento da narrativa, Aschenbach começa a oscilar entre a vontade de "salvar" Tadzio e sua família e não se desligar do rapaz, admitindo que não mais poderia viver se isso acontecesse. Outro sinal inegável de morte se observa no pesadelo que assola o protagonista na madrugada, corroborando a associação entre declínio da masculinidade hegemônica, doença, peste e decadência:

Deste sonho o atribulado acordou enervado, perturbado e enfraquecido, à mercê do demônio. Não temia mais os olhares observadores da gente; se se expunha às suas suspeitas, não lhe importava. Além disso, fugiam, começavam a partir; inúmeras cabinas estavam vazias, a ocupação da sala de jantar apresentava vácuos e, na cidade, raras vezes ainda se via algum estrangeiro. A verdade parecia ter ressumado e o pânico, apesar da rija solidariedade dos interessados, não pode ser mais refreado. (MANN, 1979, p. 162-163)

É paralelo a isso o surgimento de uma nova identidade performática, sendo que a doença e inconscientemente, o prenúncio de morte certa faça com que Aschenbach abra 
mão do padrão de masculinidade hegemônica e queira tornar-se mais vaidoso, como se isso lhe garantisse a passagem para um universo mais jovem. Uma mudança ainda mais significativa em sua aparência se observa na cena em que é maquiado pelo barbeiro, o que faz com que ele seja equiparado ao velho caricato que encontrou no barco no início da narrativa, e que ele mesmo percebeu com grande desdém:

Aschenbach, descansando confortavelmente, incapaz de uma reação, ao contrário, excitado esperançosamente pelo que se passava, viu no espelho suas sobrancelhas arquearem-se mais decisivas e simétricas, o corte de seus olhos prolongar-se, o brilho deles aumentar com uma ligeira pintura de pálpebras, viu mais abaixo, onde a pele fora de um moreno encorreado, com uma aplicação suave, aparecer um carmim delicado, seus lábios anêmicos, ainda há pouco, avolumaram-se cor de framboesa, as rugas das faces, da boca, dos olhos, desapareceram sob o creme e sopro da juventude - avistou, com o coração palpitando, um jovem florescente. (MANN, 1979, p. 164)

A descrição da transformação do velho escritor em “jovem florescente” corresponde a uma performance social que corrobora uma configuração de gênero que rompe com a constituição de masculinidade hegemônica, pois traços de feminilidade são incorporados à aparência de Aschenbach: "O deslumbrado saiu feliz como num sonho, desconcertado e medroso. Sua gravata vermelha, seu chapéu de palha de aba larga era circundado por uma fita multicolorida” (MANN, 1979, p. 165).

Ao seguir Tadzio pelas ruas de Veneza, o escritor consome frutas contaminadas pela cólera hindu, ignorando os sintomas da doença até a manhã de sua morte, quando descobre que o rapaz também irá partir. O ar de verão que havia ensejado sua paixão pelo rapaz dá lugar a um "ar suspenso, outonal" sob a praia, sinalizando o desfecho trágico do personagem. Tadzio se torna a chave para a passagem da vida para a morte, como se fosse a moeda de ouro que faltava para o gondoleiro Caronte, ainda mais se considerarmos que o rapaz é descrito, no último parágrafo da narrativa, como "psicagogo", isto é, aquele que conduzia as almas ao mundo dos mortos. É interessante observar uma correlação entre Tadzio e Aschenbach no que diz respeito à proximidade com a morte, pois o rapaz se envolve em uma briga com Jaschu, cuja força simboliza a masculinidade hegemônica que subjuga o adversário mais fraco e com características femininas: 
Mas, como se na hora da despedida o sentimento serviçal do inferior se transformasse em cruel brutalidade e parecia querer vingar-se de uma longa escravatura, o vencedor ainda não largou o vencido, porém, ajoelhado sobre suas costas, apertou o rosto de Tadzio tão seguidamente na areia que Tadzio, já sem fôlego de luta, ameaçava sufocar-se. Seus esforços de derrubar o opressor eram convulsivos, passaram completamente por momentos e se repetiam só como um estremecer. (MANN, 1979, p. 169)

Adorador e adorado estão, portanto, às portas da morte, sendo que Tadzio, muito pálido, consegue escapar. A morte chega para Aschenbach na ilusão de que o rapaz lhe acena de longe:

Mas pareceu-lhe que o pálido e gracioso psicagogo lá fora lhe sorria, lhe encenava, como se, soltando a mão dos quadris, apontasse para fora, flutuando na sua frente para a imensidão auspiciosa. E, como tantas vezes, levantou-se para segui-lo. (MANN, 1979. p. 170)

Preso ao ambiente de umidade, calor, sujeira e peste, Aschenbach se despede da vida e do objeto de sua paixão, indo de encontro à enseada cinza guiado pelo condutor de almas. A derrocada da masculinidade hegemônica é simbolizada tanto pelo escritor quanto por Jaschu, derrocada esta que se torna possível a partir do momento em que ambos os personagens se deixam dominar pela beleza andrógina de Tadzio, bem como pelo ideal artístico que esta beleza representa, no caso de Aschenbach. O homoerotismo considerado tabu se consuma a partir da idealização da beleza do jovem rapaz, em movimento que permite ao escritor transitar por um universo simbolizado pela fétida e contaminada Veneza que causa, ao fim e ao cabo, a sua própria morte.

\section{Considerações finais}

Veneza foi o cenário de inspiração por excelência de muitos escritores alemães por ser uma cidade exótica, permeada pela herança da cultura greco-latina que perpassa toda a ação de Morte em Venez̧a. O próprio Thomas Mann, conforme já explicitado, passou férias na cidade, local onde teria conhecido o rapaz polonês que lhe inspirou a escrever uma de suas mais famosas novelas. 
Para atingir os propósitos esboçados neste artigo, foi possível perceber que Mann retrata uma configuração de masculinidade hegemônica marcada pelo que Judith Butler chama de heteronormatividade, que sofre uma ruptura por meio da representação do homoerotismo enquanto veículo na busca de um ideal artístico. As representações homoeróticas são construídas em correlação com condições climáticas e atmosféricas, corroborando a importância dos elementos materiais para a compreensão da derrocada de uma masculinidade que percebe a homossexualidade como tabu e a insere na esfera da idealização como tentativa de manter seu poder hegemônico.

A ambiência da narrativa encontra respaldo na cultura e na mitologia gregas por meio das referências a Eros, Caronte e o Fédon, de Platão, o que reforça a existência de uma cultura e de uma literatura forjada por homens. Observa-se uma feminização do personagem Tadzio, que subjuga Aschenbach e seu amigo Jaschu por meio do fascínio gerado por sua incomparável beleza. É importante ressaltar que o rapaz polonês sabe que está sendo observado, tanto pelos jovens que o cercam quanto por Aschenbach que o persegue até o final da novela, o que mostra que possui consciência da atração que exerce sobre os outros personagens.

Neste processo, Aschenbach também se torna mais feminino, o que se comprova pela ida ao barbeiro, que o maquia e afirma que ele está pronto para se apaixonar. Utilizouse o conceito de performance para analisar o abalo da masculinidade hegemônica por meio da transformação operada pelo barbeiro, transformação esta induzida, sobremaneira, pelas condições climáticas de Veneza, que, com seu clima abafado e ruas contaminadas pela cólera, acaba por influenciar diretamente as disposições corporais e o modo de agir do protagonista. A atmosfera de morte e decadência é reforçada pelo barco baladesco assemelhado a um caixão, pelos barqueiros que remetem a Caronte e pelo senhor idoso que tenta parecer mais jovem do que realmente é, prenunciando as atitudes excêntricas do próprio Aschenbach em sua busca pela beleza de Tadzio enquanto ideal artístico e, porque não dizer, em sua busca por si mesmo e pela própria juventude perdida. A praia, em sua gradação entre a cor cinza que remete à morte e as cores claras que remetem ao verão, revela a 
oscilação entre o novo e o velho, assim como a passagem da vida para a morte mediada pelo próprio Tadzio, o psicagogo condutor de Aschenbach ao mundo dos mortos.

\title{
GENDER AND PRODUCTION OF HOMOEROTIC PRESENCE IN THE CONSTRUCTION OF THE MASCULINE IN DEATH IN VENICE, BY THOMAS MANN
}

\begin{abstract}
This article intends to analyze the relationships between homoeroticism, ambience and Stimmung in the construction of masculinities in Death in Venice, by Thomas Mann (1911). The research intends to work with the concepts of gender and performance proposed by Joan Scott, Teresa de Lauretis and Judith Butler, respectively, establishing relationships with the concepts developed by Hans Ulrich Gumbrecht in Atmosphere, Mood and Stimmung (2014). Our aim is to understand the role of gender constructions in the representation of homoeroticism constructed through textual material elements related to the ambience of the narrative, and through elements of Greek mythology, which can be seen in Thomas Mann's text.
\end{abstract}

KEYWORDS: Ambience; Gender; Homoeroticism; Performance; Stimmung.

\section{REFERÊNCIAS}

BUTLER, Judith. Problemas de gênero: feminismo e subversão de identidade. Rio de Janeiro: Civilização Brasileira. 2003.

. Os atos performativos e a constituição do gênero: um ensaio sobre fenomenologia e teoria feminista. Trad. Jamille Pinheiro Dias. Caderno de leituras n. 78, Chão da Feira, 2018, p. 1-16. Disponível em:< http://chaodafeira.com/wp-content/uploads/2018/06/caderno_de_leituras_n.78-final.pdf> Acesso em: 12/12/2019.

GUMBRECHT, Hans Ulrich. Produção de presença: o que o sentido não consegue transmitir. Rio de Janeiro: Contraponto: Ed. PUC - Rio, 2010.

- Atmosfera, Ambiência, Stimmung: Sobre um potencial oculto da literatura. Rio de Janeiro: Contraponto: Editora PUC Rio, 2014.

LAURETIS, Teresa de. A tecnologia do gênero. In: HOLLANDA, Heloísa Buarque de (org.) Tendências e impasses: o feminismo como crítica da cultura. Rio de Janeiro: Rocco, 1994. P. 206-241.

MANN, Thomas. Morte em Veneza. São Paulo: Abril Cultura, 1979.

RICHARD, Nelly. Intervenções críticas, arte, cultura, gênero e política. Belo Horizonte; Editora UFMG, 2002.

SCOTT, Joan. Gênero: uma categoria útil de análise histórica. New York, Columbia University Press. 1989. 
ZANINI, Eduardo Oliveira. Leitura do imaginário na poesia lírica: uma viagem na barca de Caronte com Pedro Tamen. Disponível em: < http://alb.org.br/arquivo-morto/edicoes_anteriores/anais17/txtcompletos/sem04/COLE_3736.pdf >.Acesso: 19/12/2019.

ZUMTHOR, Paul. Performance, recepção, leitura. Trad. Jerusa Pires e Suely Fenerich. São Paulo: Cosac Naify, 2007.

WILDE, Oscar. O retrato de Dorian Gray. Rio de Janeiro: L\&PM, 2001.

Recebido em: 23/12/2019.

Aprovado em: 20/05/2020. 